\title{
Adequacy And Utilization Of Tools And Equipment And Students' Performance In Technical Vocational And Livelihood Education
}

\author{
Maria Cecilia A. Mañanita \\ cez080273@gmail.com \\ Valenzuela National High School \\ DOI: 10.29322/IJSRP.11.08.2021.p11633 \\ http://dx.doi.org/10.29322/IJSRP.11.08.2021.p11633
}

\begin{abstract}
The study aimed to assess the adequacy and utilization of instructional materials in teaching Technical-Vocational and Livelihood Subject in Obando Senior High School during the School Year 2017-2018. The respondents of the study were the one (1) teacher and eleven (11) learners in cookery and bread and pastry making of Obando School of Fisheries, and one (1) teachers and nineteen (19) learners in bread and pastry, and sixty one (61) learners in cookery of Obando Stand Alone Senior High School. The study revealed that the adequacy and utilization of instructional tools and equipment in Cookery 1 and 2 are in the moderate level. In terms of adequacy of the tools and equipment is in the moderate level, while there is no evidence that the equipment were utilize in Cookery 1 and 2. It is concluded that there is a significant relationship between the adequacy of equipment and materials used and the students' academic performance in Cookery, while no significant relationship exist between the adequacy of equipment and materials and the students' academic performance in Bread and Pastry Production.
\end{abstract}

Index terms : Adequacy, technical vocational and livelihood education, utilization of tools and equipment, students' performance

\section{INTRODUCTION}

In recent years, most research in technical and vocational education focus on utilization of facilities in Technology and Livelihood Education, an old subjects in High School in the previous curriculum. This contention is manifested by some studies reviewed as one of the significant justification of the present study.

Limon (2016) conducted a study on a relationship between the quality of school facilities and student performance and achievement in the Technology and Livelihood Education (TLE). Results revealed that the component with the highest mean rating was the exterior environment (3.50) and the component with the lowest mean rating was support space (2.97). In terms of student performance and achievement, the largest increase was observed during school year 2010-2011 (22.0\%) while the smallest increase was noted during school year 2009-2010 (2.8\%). Olayinka (2016) concluded that those students who were taught with instructional materials perform better than those taught without the instructional materials. Apagu, and Wakili (2015) revealed the availability and utilization, the benefits and challenges of ICT facilities in teaching and learning vocational and technical education in Yobe state technical college. The study revealed that ICT facilities were lacking in technical colleges. Teachers and students exposure to ICT facilities was low. Moreover, Gregorio (2016) revealed the depth and how the researcher can be of help to the TLE teachers to overcome these problems by working out recommendations to lessen the burden of TLE teachers especially in using remedial measures in the absence of facilities or equipment. In addition, Caballero and Cabahug (2015) in their article loaded that the DepEd is not ready to implement the TVL track due to lack of facilities and equipment. This information is strengthened with the researcher's personal observation and experience in the schools. Akinfolarin, Ajayi and Oloruntegbe (2012) dealt with required resources in Vocational Technical Education, its availability and adequacy. The major resources which were identified and researched into are utilization of space and physical resources in Vocational and Technical Education in selected Colleges of Education in South West Nigeria.

The studies reviewed failed to correlate the relationship between the adequacy and utilization of tools and equipment and performance of the learners in Technical and Vocational Livelihood Track under the Senior High School Program. This is the gap identified in the study. If the study was not conducted, there will be no records or reports which will explain the importance on Adequacy and Utilization of tools and equipment in the recent subject in TVL subjects as it relate to the performance of the learners in instruction.

The objective of the study was to the adequacy and utilization of instructional materials relate to the performance of the learners in Cookery and Bread and Pastry Production. 


\section{MATERIALS AND METHODS}

The study made use of descriptive method is used in collecting data to demonstrate the relationship and collect the necessary information needed in the study. Since, the study aims to find out the adequacy and utilization of the tools and equipment used in teaching Cookery and Bread and Pastry Production and its relation to the performance of the learners.

The design made use of the academic performance or semestral grades of the learners in Cookery and Bread and Pastry, and the questionnaire checklists on adequacy and utilization of equipment. It made use of the purposive sampling technique, a non-probability technique, respondents were composed of one (1) teacher handling Cookery, and Bread and Pastry Production and 11 learners in Cookery and 11 learners Bread and Pastry Production enrolled in Obando School of Fisheries; two (2) teachers handling in Cookery and BPP, and 19 learners in Bread and Pastry Production, and 61 learners in Cookery of Obando Stand Alone Senior High School. In total, there were 3 teachers and 102 learners involved in this study. These respondents were totally enumerated because of the limited respondents. In other words, all of these teachers and learners were considered as sources of data needed in this study.

The questionnaire for Cookery consists of five (5) items such as measuring tools, cutting tools, mixing tools, kitchen utensil, and equipment. Likewise, questionnaire for Bread and Pastry Production consists of instructional tools and equipment such as measuring, cutting, mixing, baking, decorating, kitchen utensils and equipment. The list of instructional tools and equipment is based on the recommendation of TESDA prescribed in the Training Regulations Manual for Cookery and Bread and Pastry Production.

The questionnaire was validated by the master teachers in Cookery and Bread and Pastry Production in Valenzuela National High School. The questionnaire was piloted to fifteen (15) learners in same school.

The questionnaire was scored using the following.

Scale Range Adequacy Utilization

$\begin{array}{llcl}5 & 4.21-5.00 & \text { Very Much Adequate } & \text { Very Much Utilized } \\ 4 & 3.41-4.20 & \text { Much Adequate } & \text { Much Utilized } \\ 3 & 2.61-3.40 & \text { Moderately Adequate } & \text { Moderately Utilized } \\ 2 & 1.81-2.60 & \text { Less Adequate } & \text { Less Utilized } \\ 1 & 1.00-1.80 & \text { Not Adequate } & \text { Not Utilized }\end{array}$

Another tool used in attaining the objectives of the study was the inventory of tools and equipment in Cookery and Bread and Pastry Production through the use of inventory sheet. The inventory sheet was composed of two parts. Part I is the profile of the teachers and Part II is the inventory of the different tools in Bread and Pastry.

\section{RESULTS AND DISCUSSIONS}

Level of adequacy and utilization of instructional tools and equipment used in Cookery and Bread and Pastry Production

Table 1 presents the mean scores on the adequacy and utilization of instructional tools and equipment in Module 2 in Cookery.

Table 1. Mean Scores on the Adequacy and Utilization of Instructional Tools and Equipment in Module 1 in Cookery

\begin{tabular}{|l|l|l|l|l|}
\hline \multirow{2}{*}{$\begin{array}{c}\text { Instructional Tools and } \\
\text { Equipment }\end{array}$} & \multicolumn{2}{|c|}{ Adequacy } & \multicolumn{2}{c|}{ Utilization } \\
\cline { 2 - 6 } & Mean & \multicolumn{1}{c|}{ Verbal Interpretation } & Mean & Verbal Interpretation \\
\hline 1. Measuring Tools & 3.42 & Much Adequate & 2.99 & Moderately Utilized \\
\hline 2. Cutting Tools & 3.12 & Moderately Adequate & 2.40 & Less Utilized \\
\hline 3. Mixing Tools & 3.90 & Much Adequate & 3.61 & Much Utilized \\
\hline 4. Kitchen Utensils & 3.20 & Moderately Adequate & 2.75 & Moderately Utilized \\
\hline 5. Equipment & 3.18 & Moderately Adequate & 1.46 & Not Utilized \\
\hline \multicolumn{1}{|c|}{ Average } & $\mathbf{3 . 3 6}$ & Moderately Adequate & $\mathbf{2 . 6 4}$ & Moderately Utilized \\
\hline
\end{tabular}

The table shows that the cutting tools used in teaching Module 1 in Cookery has the highest mean score of 3.90 verbally interpreted as Much Adequate, while cutting tools has the lowest mean score of 3.12 verbally interpreted as Moderately Adequate. The average mean score of the instructional tools and equipment used in teaching Module 1 in Cookery is 3.36. On the other hand the utilization of mixing tools in Module 1 in Cookery has mean score of 3.61 verbally interpreted as Much Utilized and equipment has mean score of 1.46 verbally interpreted as Not Utilized. This means that there were available equipment but not utilized.

Although there is no utilization of equipment, yet the average mean on the utilization of instructional tools in Cookery 1 . This emphasizes that the schools value the significance of instructional tools in teaching Cookery. 
Table 2. Mean Scores on the Adequacy and Utilization of Instructional Tools and Equipment in Module 2 in Cookery

\begin{tabular}{|l|l|l|l|l|}
\hline \multirow{2}{*}{$\begin{array}{c}\text { Instructional Tools } \\
\text { and Equipment }\end{array}$} & \multicolumn{2}{|c|}{ Adequacy } & \multicolumn{2}{c|}{ Utilization } \\
\cline { 2 - 5 } & Mean & \multicolumn{1}{|c|}{ Verbal Interpretation } & \multicolumn{1}{c|}{ Mean } & \multicolumn{1}{c|}{ Verbal Interpretation } \\
\hline 1. Measuring Tools & 3.23 & Moderately Adequate & 2.93 & Moderately Utilized \\
\hline 2. Cutting Tools & 3.19 & Moderately Adequate & 2.42 & Less Utilized \\
\hline 3. Mixing Tools & 4.20 & Much Adequate & 3.52 & Much Utilized \\
\hline 4. Kitchen Utensils & 3.18 & Moderately Adequate & 2.83 & Moderately Utilized \\
\hline 5. Equipment & 3.18 & Moderately Adequate & 1.38 & Not Utilized \\
\hline Average & $\mathbf{3 . 4 0}$ & Moderately Adequate & $\mathbf{2 . 6 1}$ & Moderately Utilized \\
\hline
\end{tabular}

The table shows that the mixing tools used in teaching Module 2 in Cookery has the highest mean score of 4.20 verbally interpreted as Much Adequate, while kitchen utensils and equipment have a mean score of 3.18 verbally interpreted as Moderately Adequate. The average mean score in the adequacy of the instructional tools and equipment used in teaching Module 2 in Cookery is 3.36. On the other hand the utilization of mixing tools in Module 2 in Cookery has mean score of 3.52 verbally interpreted as Much Utilized and equipment has mean score of 1.38 verbally interpreted as Not Utilized. Although there is no utilization of equipment, yet the average mean on the utilization of instructional tools in Cookery 2 as indicative of the means score of 2.61. It can be deduced from this result that

the teacher handling Cookery 2 utilized the tools and equipment in Cookery 2.

Table 3. Mean Scores on the Adequacy and Utilization of Instructional Tools and Equipment in Bread and Pastry Production

\begin{tabular}{|c|c|c|c|c|}
\hline \multirow{2}{*}{$\begin{array}{l}\text { Instructional Tools and } \\
\text { Equipment }\end{array}$} & \multicolumn{2}{|r|}{ Adequacy } & \multicolumn{2}{|r|}{ Utilization } \\
\hline & Mean & Verbal Interpretation & Mean & Verbal Interpretation \\
\hline 1. Measuring Tools & 2.20 & Less Adequate & 2.24 & Less Utilized \\
\hline 2. Cutting Tools & 3.87 & Much Adequate & 3.65 & Much Utilized \\
\hline 3. Mixing Tools & 3.49 & Much Adequate & 3.44 & Much Utilized \\
\hline 4. Baking Tools & 3.36 & Much Adequate & 3.28 & Moderately Utilized \\
\hline 5. Decorating Tools & 3.19 & Moderately Adequate & 2.97 & Less Utilized \\
\hline 6. Kitchen Utensils & 3.45 & Much Adequate & 3.18 & Moderately Utilized \\
\hline 7. Equipment & 2.95 & Moderately Adequate & 2.95 & Moderately Utilized \\
\hline Average & 3.21 & Moderately Adequate & 3.10 & Moderately Utilized \\
\hline
\end{tabular}

The table shows that the mixing tools used in teaching bread and pastry has the highest mean score of 3.87 verbally interpreted as Much Adequate, while measuring tools has the lowest mean score of 2.20 verbally interpreted as Less Adequate. The average mean score in the adequacy of the instructional tools and equipment used in teaching bread and pastry is 3.21 verbally interpreted as less adequate. On the other hand, The highest mean score on the utilization of the instructional tools and equipment in bread and pastry is 3.65 verbally interpreted as Moderately utilizes. The lowest mean score is 2.24 verbally interpreted as less utilized. Generally, the average mean score in the utilization of the instructional tools and equipment in bread and pastry production is 3.10 verbally interpreted as Moderately Utilized. The findings indicate that the tools and equipment which are adequately provided by the schools are utilized by the teachers teaching Bread and Pastry Production.

\section{Significant Relationship between Adequacy and Performance of the Respondents in Cookery 1 and 2 and Bread and Pastry Production}

To test how adequacy and utilization of instructional tools and equipment relate to the students' performance in Cookery and Bread and Pastry Production, Pearson $r$ for testing the significance of $r$ was used

Table 4. Significant Relationship between Performance and Utilization of the Respondents in Cookery 1 \& 2 and Bread and Pastry Production

\begin{tabular}{|c|c|c|c|c|}
\hline $\begin{array}{c}\text { Instructional Tools and } \\
\text { Equipment }\end{array}$ & r-value & p-value & Ho & VI \\
\hline
\end{tabular}

This publication is licensed under Creative Commons Attribution CC BY. 


\begin{tabular}{|l|l|l|l|l|}
\hline Cookery Module 1 & 0.889 & 0.000 & Reject & Significant \\
\hline Cookery Module 2 & 0.258 & 0.028 & Reject & Significant \\
\hline Bread and Pastry Production & 0.859 & 0.000 & Accept & Not Significant \\
\hline
\end{tabular}

Table 4 presents that the $p$-value on testing the significance of $r$ on the relationship between the utilization of tools and equipment and performance of the respondents based on their grades in Module 1 in Cookery at 0.05 level of significance is 0.000 with a decision to reject the null hypothesis interpreted as significant.

Moreover, the $p$-value on testing the significance of $r$ on the relationship between the utilization of tools and equipment and performance of the respondents based on their grades in Module 2 in Cookery at 0.05 level of significance is 0.028 with a decision to accept the null hypothesis interpreted as significant.

However, the $p$-value on testing the significance of $r$ on the relationship between the utilization of tools and equipment and performance of the respondents based on their grades in Bread and Pastry Production at 0.05 level of significance is 0.217 with a decision to accept the null hypothesis interpreted as not significant.

The data explains that the instructional tools and equipment in very important in the quality of instruction in Cookery. Akinfolarin, Ajayi and Oloruntegbe (2012) revealed that the adequacy of resources paved the way to the quality instruction particularly in the development of skills in Technical Education. However, it is not related to the performance of the students in Bread and Pastry. This contradict the findings of Limon (2016) who revealed that insufficient school facilities were negatively impacting student performance and achievement, and the administrators concerned take no significant action in addressing this educational issue. Since the lack of educational facilities was proven to pose serious ramifications on student performance and achievement, stakeholders should closely look into procedures that focus on facility support and management in the field of TLE.

The findings imply that instructional tools and equipment are really important to the performance of the students TechnicalVocational Livelihood Education Subjects.

\section{CONCLUSION}

The adequacy and utilization of instructional tools and equipment in Cookery 1 and 2 are in the moderate level. In terms of adequacy of the tools and equipment is in the moderate level, while there is no evidence that the equipment were utilize in Cookery 1 and 2. There is a significant relationship between the adequacy of equipment and materials used and the students' academic performance in Cookery, while no significant relationship exist between the adequacy of equipment and materials and the students' academic performance in Bread and Pastry Production.

\section{REFERENCES}

Akinfolarin, C.A., Ajayi, I. A., Oloruntegbe, K. O. (2012). An Appraisal of Resource Utilization in Vocational and Technical Education in Selected Colleges of Education in Southwest Nigeria. Scientific and Academic Publishing. Akungba-Akoko, Ondo State. doi: 10.5923/j.edu.20120201.08. Retrieved from http://article.sapub.org/10.5923.j.edu.20120201.08.html

Apagu, V.V., Wakili, B. A. (2015). Availability and Utilization of Ict Facilities for Teaching and Learning of Vocational and Technical Education in Yobe State Technical Colleges. American Journal of Engineering Research (AJER) Volume-04, Issue-02, pp113-118. Retrieved from www.ajer.org/papers/v4(02)/N04201130118.pdf

Caballero F. R., Cabahug, R. G. (2015). The K to 12 Senior High School Technical-Vocational Livelihood Track is Not at All Ready for Implementation. JPAIR, Vol. 5 No. 1

Gregorio, S. R. (2016). Technology and Livelihood (TLE) Instruction of Technical Vocational and Selected General Secondary Schools in Catanduanes International Journal of Learning, Teaching and Educational Research. Vol. 15 , No. 4.

Limon, M.R. (2016). The Effect of the Adequacy of School Facilities on Students' Performance and Achievement in Technology and Livelihood Education.Vol. 5, No.1. Retrieved from https:///www.hrmars.com/hrmars_papers

Olayinka, A. B. (2016). Effects of Instructional Materials on Secondary Schools Students'Academic Achievement in Social

Studies in Ekiti State, Nigeria. World Journal of Education, Vol. 6, No. 1. http://dx.doi.org/10.5430/wje.v6n1p32

First Author - Maria Cecilia A. Mananita, Master of Technology and Home Economics, cez080273@gmail.com

Correspondence Author - Maria Cecilia A. Mananita, Master of Technology and Home Economics, cez080273@gmail.com 
International Journal of Scientific and Research Publications, Volume 11, Issue 8, August 2021 